\title{
Forecasting European Economic Policy Uncertainty
}

\author{
Stavros Degiannakis ${ }^{1,2}$ and George Filis ${ }^{3, *}$ \\ ${ }^{1}$ Department of Economics and Regional Development, Panteion University of Social \\ and Political Sciences, 136 Syggrou Avenue, 17671, Greece. \\ ${ }^{2}$ Postgraduate Department of Business Administration, Hellenic Open University, \\ Aristotelous 18, 26 335, Greece. \\ ${ }^{3}$ Department of Accounting, Finance and Economics, Bournemouth University, 89 \\ Holdenhurst Road, BH8 8EB, Bournemouth, UK \\ *Corresponding author: email: gfilis@bournemouth.ac.uk
}

\begin{abstract}
Forecasting the economic policy uncertainty in Europe is of paramount importance given the on-going sovereign debt crisis. This paper evaluates monthly economic policy uncertainty index forecasts and examines whether ultra-high frequency information from asset market volatilities and global economic uncertainty can improve the forecasts relatively to the no-change forecast. The results show that the global economic policy uncertainty provides the highest predictive gains, followed by the European and US stock market realized volatilities. In addition, the European stock market implied volatility index is shown to be an important predictor of the economic policy uncertainty.
\end{abstract}

Keywords: Economic policy uncertainty, forecasting, financial markets, commodities markets, HAR, ultra-high frequency information.

JEL: C22, C53, E60, E66, G10. 


\section{Introduction}

Although the effects of policy uncertainty on economic conditions have attracted the interest of academic research for over 35 years (see, for instance, Marcus, 1981; Bernanke, 1983; Colombo, 2013), such interest has reemerged since the Global Financial Crisis of 2007-2009, the European sovereign debt crisis since 2010, as well as, more recently with the Trump's win in the US elections and the UK's referendum vote for Brexit (Antonakakis et al., 2013; New York Times, 2016; Bloomberg, 2017; Caggiano et al., 2017).

The economic uncertainty is a key determinant of the business cycle and its effects on economic activity is mainly propagated either through household consumption decisions and delays in firms' hiring plans or via delays in the investment activity in physical capital (Visco, 2017). More specifically, households tend to postpone spending and increase their precautionary savings when there is uncertainty surrounding monetary and fiscal policy decisions. Along a similar vein, when economic policy uncertainty is high, firms postpone their investment plans, given the irreversibility of such decisions (Pindyck, 1990), which results in lower productivity and higher levels of unemployment (Bloom, 2009; Bloom et al., 2012; Bloom, 2014). Kang et al. (2014) second these findings, arguing further that when the real sector is faced with uncertainty regarding future decisions in terms of health care costs, tax codes or changes in regulations, then it tends to delay investment plans. Such effects are particularly evident during recession periods. Wang et al. (2015) maintain that economic policy uncertainty could also impact the financial markets and thus financial decisions.

Despite the importance of economic policy uncertainty in economic developments, there is not systematic effort to forecast it, so to allow policy makers and economic agents to act upon such forecasts. So far, there is only one study that examines the predictive information of commodity prices on economic policy uncertainty by Wang et al. (2015). By contrast, recent studies have primarily tried to examine the predictive content of economic policy uncertainty on either US recessions (Karnizova and Li, 2014) or stock market volatility (Liu and Zhang, 2015).

Even more, there is a strand in the literature showing that economic policy uncertainty is not only related to monetary and fiscal decisions, but it is also impacted by financial and commodities markets. For instance, Beckmann and Czudaj (2017a) and Bekiros and Uddin (2017) show that there is a link between exchange rates and 
economic policy uncertainty. Furthermore, studies show that changes in oil price shocks or stock market conditions trigger changes in economic policy uncertainty (Antonakakis et al., 2013; Kang and Ratti, 2013; Antonakakis et al., 2014; Ko and Lee, 2015; Berger and Uddin, 2016; Bekiros and Uddin, 2017). Even more, Wang et al. (2015) provide evidence that commodity price changes act as leading indicators of the US economic policy uncertainty. Hence, we maintain that asset volatilities could also contain important predictive information for the economic policy uncertainty.

Thus, this paper aims to fill this void and assess whether asset price volatilities provide predictive gains on European economic policy uncertainty index (developed by Baker et al., 2016) forecasts for the period 2003-2015 ${ }^{1}$. We choose to focus in Europe, due to the ongoing sovereign debt and financial crisis, as well as, the announcement of the UK's referendum, which have taken place during our sample period.

The rest of the paper is structured as follows. Section 2 describes the data used and Section 3 outlines the forecasting models. Section 4 provides an analysis of the findings; Section 5 investigates the validity of our results across several robustness tests, whereas Section 6 concludes the study.

\section{Data Description}

In this study we employ monthly data from Baker et al. (2016) European economic policy uncertainty (EPU) index, as well as, tick-by-tick front-month futures contracts data of two major European stock market indices (FTSE100 and Eurostoxx 50) and two major currencies (GBP/USD and EUR/USD). We further consider whether global economic conditions and asset markets could also provide predictive information to the EPU forecast. Thus, tick-by-tick front-month futures contracts of the S\&P500 stock index (proxy for global stock market), Brent crude oil (proxy for commodities market) and US 10 year T-bills $^{2}$ (proxy for global economic developments) and monthly data from the Global EPU are also used in this study. The tick-by-tick data are used to construct monthly realized volatilities for the

\footnotetext{
${ }^{1}$ It is beyond the scope of this paper to evaluate other indicators (such as political or macroeconomic, such as Hasset and Sullivan's (2016) expectations about tax changes, Jurado's et al. (2015) macroeconomic uncertainty index or real-activity factors and uncertainty indices by Scotti (2016)) that could also provide predictive information for the economic policy uncertainty in Europe.

${ }_{2}$ Tick-by-tick data for European 10year sovereign bonds are not available and thus they are not considered in this study.
} 
aforementioned assets (see Appendix 1 for the technical details). Table 1 presents the data used in the study.

\section{[TABLE 1 HERE]}

The period of our study spans from August, 2003 to August, 2015 (T=145 months) and it is dictated by the availability of intraday data for the Brent Crude oil futures contracts. Table 2 presents the descriptive statistics of the series.

[TABLE 2 HERE]

We show that EPU and GEPU are very volatile, relatively to the volatilities of the remaining asset classes. Furthermore, the Brent crude oil exhibits the higher average volatility compared to the remaining assets, as well as, the highest standard deviation, followed by the Eurostoxx 50 and FTSE100 volatilities. By contrast, the lowest volatilities are associated with the US T-bill and the two currencies of our series. Finally, all variables exhibit non-normality, as suggested by the Jarque-Bera test, skewness and kurtosis.

\section{Forecasting models}

We should highlight here again that European economic policy uncertainty has not been forecasted before, and thus we need to select a model that is well established in the literature of being able to successfully forecast uncertainty. The financial literature has shown that Corsi's (2009) Heterogeneous AutoRegressive model is capable of modelling and forecasting financial uncertainty, as approximated by asset price realized volatility (see, inter alia, Andersen et al., 2007). Hence, we maintain that this is an appropriate framework for modelling and forecasting economic uncertainty. Degiannakis and Filis (2017) further proposed the HAR-X model incorporating information from exogenous assets. In our case, the HAR-X model for the $E P U_{t}$ is employed for monthly data in the form:

$$
\begin{gathered}
\log \left(E P U_{t}\right)=w_{0}+w_{1} \log \left(E P U_{t-1}\right)+w_{2}\left(3^{-1} \sum_{k=1}^{3} \log \left(E P U_{t-k}\right)\right)+ \\
w_{3}\left(12^{-1} \sum_{k=1}^{12} \log \left(E P U_{t-12}\right)\right)+w_{4} \log \left(R V_{x, t-1}^{(M)}\right)+ \\
w_{5}\left(3^{-1} \sum_{k=1}^{3} \log \left(R V_{x, t-k}^{(M)}\right)\right)+w_{6}\left(12^{-1} \sum_{k=1}^{12} \log \left(R V_{x, t-k}^{(M)}\right)\right)+\varepsilon_{t},
\end{gathered}
$$

where $\varepsilon_{t}$ is a white noise and $R V_{x, t-k}^{(M)}$ denotes the monthly realized volatility of the exogenous asset for $t-k$ month. When the Global EPU is the exogenous variable, the $R V_{x, t-k}^{(M)}$ is replaced with $G E P U_{t-k}$. The proposed HAR-X model incorporates 
information of the previous month's, quarters' and year's $E P U_{t}$ and $R V_{x, t-k}^{(M)}$. Thus, the summation of uncertainty measure and realized volatility at different time horizons accommodates the volatility persistence and long-memory behavior detected in financial markets.

Apart from the HAR-X models, we further estimate the no-change forecast, an AR(1) model and a simple HAR model without any exogenous variable.

The forecasts are estimated using a rolling window approach with a fixed window length of 100 months, leaving 45 months for our out-of-sample period. The rolling window approach was chosen to account for the potential instability in the models' parameters or structural breaks in the series. It is rather typical in the forecasting exercise to leave approximately $T / 3$ observations for the out-of-sample forecasts (see for instance, Silva and Hassani, 2015; Marcellino et al., 2003). Thus, the in-sample period spans from August, 2003 until November, 2011, whereas the out-of-sample period is from December, 2011 to August, 2015.

The forecasting ability is initially evaluated using the Mean Squared Predicted Error (MSPE) and the Mean Absolute Percentage Predicted Error (MAPPE). Further, we use the Model Confidence Set (MCS) of Hansen et al. (2011) so as to identify the set of models that exhibit equal forecasting accuracy ${ }^{3}$. The advantage of the MCS test over other approaches; e.g. Diebold-Mariano test (Diebold and Mariano, 1995), Equal Predictive Accuracy test (Clark and West, 2007) or Superior Predictive Ability test (Hansen, 2005), is that the former does not demand for a benchmark model but rather it evaluates the forecasting performance of all competing models simultaneously.

\section{Empirical analysis}

We start our analysis with the presentation of the MSPE and MAPPE results, which are shown in Tables 3 and 4. Tables 3 and 4 report the predictive gains of the competing models relatively to the no-change forecast (random walk). From these results it is clear that there is not a single model that outperforms all others at all forecasting horizons. Although, most HAR-X models seem to outperform not only the no-change forecast, but also the AR(1) and the simple HAR model.

[TABLE 3 HERE]

[TABLE 4 HERE]

\footnotetext{
${ }^{3}$ The technical details of the MCS test can be found in Degiannakis and Filis (2017).
} 
More specifically, in the first two months of the out-of-sample forecasts we notice that the HAR-FT, HAR-XX, HAR-SP and HAR-TY are the models, which demonstrate the highest predictive ability. Nevertheless, the HAR-GEPU is the best performing model for all out-of-sample forecasting horizons after the 3-months ahead. In particular, the HAR-GEPU model provides significant predictive gains, as it improves the no-change forecast between $66 \%$ and $82 \%$ (approximately), based on the MSPE (depending on the forecasting horizon). Interestingly enough, the European exchange rate volatilities do not provide any predictive information and the same holds for the HAR-CO model. More specifically, even though these models perform better than the no-change forecast in the short run (e.g. 1-month to 5-months ahead), they are not able to outperform the $\mathrm{AR}(1)$ and HAR. In the longer run forecasting horizons the forecasts of the HAR-BP, HAR-EC and HAR-CO are becoming even worse, as they are not able to outperform the random walk forecasts.

Overall, these findings show that EPU is mainly impacted by the global economic policy uncertainty, as well as, the uncertainty surrounding the financial markets (either European or US/Global). By contrast, the exchange rate market and the leading commodity market (Brent crude oil) do not contain any predictive information. These results are also corroborated by the MCS test ${ }^{4}$, which shows that in most cases the models that are included in the set of the best predictive models are the HAR-FT, HAR-XX, HAR-SP, HAR-TY and HAR-GEPU.

Following the assessment of the forecasting accuracy of the HAR-X models, we assess their directional accuracy (Table 5), i.e. we test the capacity of the models in predicting whether EPU levels will increase or decrease in the future. For brevity, Table 5 only considers the best performing models from Tables 3 and 4 .

[TABLE 5 HERE]

From Table 5 it is evident that the HAR-GEPU model is able to provide a materially high directional accuracy, which ranges between $60.61 \%$ and $78.79 \%$. This does not hold for the 1-month ahead forecasting horizons where the directional accuracy of the HAR-GEPU model is only $51.52 \%$. Importantly, the model which also demonstrates a very high directional accuracy is the HAR-SP model, although this model was not ranked that high in terms of forecasting accuracy.

\footnotetext{
${ }^{4}$ For brevity we do not present the actual results for these tests. These are available upon request.
} 
These results suggest that the HAR-X models which are augmented with the stock market volatilities and GEPU should be used by policy makers or users who are interested in the accuracy of the forecasts, whereas those stakeholders who are mainly interested in the direction of the EPU index should not take under consideration the informational content of the European stock market volatilities.

\section{Robustness}

\section{Alternative measures of asset volatility and financial uncertainty}

In this section we examine the validity of our results using several robustness tests. First, we assess whether alternative measures of asset volatility and financial uncertainty could provide incremental predictive ability for the EPU. In particular, we employ (i) the financial uncertainty (FINUNC) index by Jurado et al. (2015) ${ }^{5}$, which is an index constructed based on the common factor of the unforecastable component of 148 financial indicators, and it has received a lot of attention in the recent literature (see, for instance, Strobel, 2015; Leduc and Liu, 2016; Beckmann and Czudaj, 2017b) and (ii) the implied volatilities for our exogenous assets. In particular, we employ the implied volatility indices of the FTSE100 (VFTSE), the Euro Stoxx 50 (VSTOXX), the GBP/USD exchange rate (VBP), the EUR/USD exchange rate (VEC), the WTI crude oil (OVX), the Brent crude oil (VBRENT) and the S\&P500 (VIX) ${ }^{6}$. The results are shown in Tables 6 and 7.

[TABLE 6 HERE]

[TABLE 7 HERE]

The results from Tables 6 and 7 suggest that none of the alternative measures are capable of producing improved forecasts compared to the best HAR-X models presented in the main analysis (see Table 5) and in particular with the HAR-GEPU. The only exception is the HAR-VSTOXX which exhibits marginally improved forecasts, relatively to the realized volatilities of our financial assets, although even in this case, these improved forecasts are not statistically more accurate. Hence, we show that the use of the realized volatilities and the implied volatility of the Eurostoxx 50 index are capable of providing the most accurate EPU forecasts. By contrast,

\footnotetext{
5 The data for the financial uncertainty index is obtained from Sydney Ludvigson's website (https://www.sydneyludvigson.com/data-and-appendixes/).

${ }^{6}$ The implied volatility index of the US 10yr T-bill is not considered due to data unavailability. Data have been obtained from Bloomberg.
} 
Jurado's et al. (2015) financial uncertainty index is a rather weak predictor of European EPU.

Economic policy uncertainty of individual European countries and the US

Next, we estimate the HAR-X models using the economic policy uncertainty indices of the individual European countries, as well as, the US. The results are presented in Tables 8 and 9.

[TABLE 8 HERE]

[TABLE 9 HERE]

Even when considering the individual countries' EPU we observe that we cannot obtain improved forecasts for the European EPU. This is also true for the US EPU, although we show that in some of the forecasting horizons, marginal predictive gains can be obtained.

\section{Incorporating asymmetries in the HAR-X model}

Another robustness test is related to the potential asymmetries that could improve our forecasts. Given that the previous robustness tests did not convincingly show that they could improve our original forecasts, we proceed in the estimation of asymmetric HAR-X models using the models in Table 3. It is reasonable to assume that positive movements in the asset volatilities and financial/economic uncertainty might have a larger impact on the European EPU, relative to the negative movements. Hence, we proceed to the estimation of an asymmetric HAR-X model, in the notion that when $\log \left(R V_{x, t-1}^{(M)}\right)>\left(12^{-1} \sum_{k=1}^{12} \log \left(R V_{x, t-k}^{(M)}\right)\right)$, the $R V_{x, t-1}^{(M)}$ has a greater impact on the European EPU index than when $\log \left(R V_{x, t-1}^{(M)}\right) \leq\left(12^{-1} \sum_{k=1}^{12} \log \left(R V_{x, t-k}^{(M)}\right)\right)$. The asymmetric HAR-X model has been defined as: 


$$
\begin{aligned}
\log \left(E P U_{t}\right)= & w_{0}+w_{1} \log \left(E P U_{t-1}\right)+w_{2}\left(3^{-1} \sum_{k=1}^{3} \log \left(E P U_{t-k}\right)\right) \\
& +w_{3}\left(12^{-1} \sum_{k=1}^{12} \log \left(E P U_{t-12}\right)\right)+w_{4} \log \left(R V_{x, t-1}^{(M)}\right) \\
& +w_{5}\left(3^{-1} \sum_{k=1}^{3} \log \left(R V_{x, t-k}^{(M)}\right)\right)+w_{6}\left(12^{-1} \sum_{k=1}^{12} \log \left(R V_{x, t-k}^{(M)}\right)\right) \\
& +w_{7} \log \left(R V_{x, t-1}^{(M)}\right) d_{t-1}+w_{8}\left(3^{-1} \sum_{k=1}^{3} \log \left(R V_{x, t-k}^{(M)}\right)\right) d_{t-1} \\
& +w_{9}\left(12^{-1} \sum_{k=1}^{12} \log \left(R V_{x, t-k}^{(M)}\right)\right) d_{t-1}+\varepsilon_{t},
\end{aligned}
$$

where, $d_{t-1}=1$, if $\log \left(R V_{x, t-1}^{(M)}\right)>\left(12^{-1} \sum_{k=1}^{12} \log \left(R V_{x, t-k}^{(M)}\right)\right)$ and zero otherwise ${ }^{7}$.

The results of the asymmetric HAR-X are shown in Tables 10 and 11 .

[TABLE 10 HERE]

[TABLE 11 HERE]

The results in Tables 10 and 11 show the percentage of improvement of the asymmetric HAR-X model relative to the equivalent symmetric HAR-X model. Thus, values below 1 suggest that the asymmetric model provides incremental predictive gains relative to the symmetric HAR.

It is rather interesting that on the whole we cannot find evidence that the asymmetric HAR-X models generate predictive gains for the European EPU. Despite this, the results from both the MSPE and MAPPE show that the asymmetric HAR-XX and the asymmetric HAR-SP do exhibit important improvements in their forecasts relative to the equivalent symmetric models, nevertheless, the former cannot outperform the best performing symmetric HAR model, namely the HAR-GEPU. It is also important to note that the MCS test provides evidence that there are no statistically significant differences in the forecasting accuracy between the symmetric and asymmetric versions of the HAR-X model.

\section{Combining forecasts}

Finally, following Wang et al. (2015) we proceed with forecast combination of the models presented on Table 3 . We use both the unweighted forecast combination

\footnotetext{
${ }^{7}$ The asymmetric HAR-X model has also been estimated for $\log \left(R V_{x, t-1}^{(M)}\right)>\left(3^{-1} \sum_{k=1}^{3} \log \left(R V_{x, t-k}^{(M)}\right)\right)$ and the results are qualitatively similar.
} 
of all models, as well as, the inverse MSPE and MAPPE weighted schemes. The results are shown in Table 11.

\section{[TABLE 11 HERE]}

In the case of the unweighted scheme, the evidence shows that there is always a HAR-X model that performs better than the forecast combination (the only exception is the 2 and 3 months ahead forecast horizon), suggesting that this approach does not provide incremental predictive gains. By contrast, we report that in some forecast horizons the weighted scheme (either based on the MSPE or MAPPE) provides incremental predictive gains relative to the HAR-X models; nevertheless, these are not statistically significant, based on the MCS test.

\section{Conclusion}

This paper forecasts for the first time the European economic policy uncertainty index, using information from European and global asset market volatilities, as well as, financial and economic uncertainty indicators. The results show that the global economic policy uncertainty offers significant predictive gains, ranging between $66 \%$ and $82 \%$, compared to the no-change out-of-sample forecasts. In addition, the information extracted from the European and US stock market realized volatilities provides materially high predictive gains for the European economic policy uncertainty index. These results also hold when we consider the directional accuracy of these models. Finally, our efforts to enhance the forecasting accuracy of the European EPU through several alternative measures, models and forecast combinations did not produce significantly incremental predictive gains. The only exception is the European stock market implied volatility index (VSTOXX), which is shown to provide qualitatively similar predictive gains with the European and US stock market realized volatilities. Therefore, the HAR-X model with global asset market realized volatilities, the European implied volatility and the global economic policy uncertainty is the most adequate framework to capture the future movements of EPU in Europe.

These results are important for policy makers who aim to maintain economic policy uncertainty at low level so to avoid reduced consumer spending and firms' underinvestment. For instance, when financial volatility, either from Europe or the US, increases, then this should alarm policy makers that the economic policy 
uncertainty will follow suit in the following months, allowing them to be proactive rather than reactive.

Finally, our findings highlight that this is a very important line of research which deserves more attention. Future work may examine the impact of the Brexit vote or the Trump's election victory on EPU forecasts of European as well as of other countries, such as the US and the UK. Furthermore, the current paper concentrates on the predictive information of the financial markets, whereas future studies could also concentrate on the predictive content of political events. For instance, as pointed out by Baker et al. (2016), the EPU index is, more than anything else, driven by political events and policy decisions - e.g., election cycles. Similarly, Davis (2017) argues that regulatory complexity fosters EPU. Hassett and Sullivan (2016) find that expectations about tax changes have an influence on EPU. Consequently, later studies could include variables in their forecasting frameworks that directly capture some of these political factors. Even more, it is important to study the predictive content of variables that are more closely linked to real economic activity and the macroeconomy, e.g. the real-activity factors and macroeconomic uncertainty indices calculated by Scotti (2016) or Jurado et al. (2015). In addition, Baker et al. (2016) also provide indices for migration policy uncertainty and migration fear for France, Germany, the UK and the US. Such variables could also be used as potential predictors of EPU. An additional avenue for further study could be related to the adoption of time-varying parameter frameworks, such as the Dynamic HAR model.

\section{Acknowledgements}

The authors would like to thank Joscha Beckmann (Guest Editor), Robert Czudaj (Guest Editor), Gary Koop (Editor), and the two anonymous reviewers for their helpful comments on a previous version of this paper. Their suggestions helped to improve the quality of the paper substantially. We would also like to thank the participants of the $16^{\text {th }}$ EEFS Annual Conference for the valuable comments. The authors acknowledge the support of the European Union's Horizon 2020 research and innovation programme, which has funded them under the Marie Sklodowska-Curie grant agreement No 658494. The usual disclaimer applies. 


\section{References}

Andersen, T.G., Bollerslev, T. \& Diebold, F.X. (2007). Roughing it up: Including jump components in the measurement, modeling, and forecasting of return volatility. The Review of Economics and Statistics, 89(4), 701-720.

Antonakakis, N., Chatziantoniou, I. \& Filis, G. (2013). Dynamic co-movements of stock market returns, implied volatility and policy uncertainty. Economics Letters, 120(1), 87-92.

Antonakakis, N., Chatziantoniou, I. \& Filis, G. (2014). Dynamic spillovers of oil price shocks and economic policy uncertainty. Energy Economics, 44, 433-447.

Baker, S.R., Bloom, N. \& Davis, S.J. (2016). Measuring economic policy uncertainty. The Quarterly Journal of Economics, 131(4), 1593-1636.

Beckmann, J. \& Czudaj, R. (2017a). Exchange rate expectations and economic policy uncertainty. European Journal of Political Economy, 47, 148-162.

Beckmann, J., \& Czudaj, R. (2017b). The impact of uncertainty on professional exchange rate forecasts. Journal of International Money and Finance, 73, 296316.

Bekiros, S., \& Uddin, G.S. (2017). Extreme Dependence under Uncertainty: an application to Stock, Currency and Oil Markets. International Review of Finance, 17(1), 155-162.

Berger, T., \& Uddin, G.S. (2016). On the dynamic dependence between equity markets, commodity futures and economic uncertainty indexes. Energy Economics, 56, 374-383.

Bernanke, B.S. (1983). Irreversibility, uncertainty, and cyclical investment. The Quarterly Journal of Economics, 98(1), 85-106.

Bloom, N. (2009). The impact of uncertainty shocks. Econometrica, 77(3), 623-685.

Bloom, N. (2014). Fluctuations in uncertainty. Journal of Economic Perspectives. 28(2), 153-176.

Bloom, N., Floetotto, M., Jairmovich, N., Saporta Eksten, I. \& Terry, S. (2012). Really uncertain business cycles. US Census Bureau Center for Economic Studies Paper No. CES-WP-14-18.

Bloomberg. (2017). Trump's uncertainty principle, Bloomberg Business Week 26/01/2017, https://www.bloomberg.com/news/articles/2017-01-26/trump-suncertainty-principle. 
Caggiano, G., Castelnuovo, E. \& Figueres, J.M. (2017). Economic policy uncertainty and unemployment in the United States: A nonlinear approach. Economics Letters, 151, 31-34.

Clark, T.E., \& West, K.D. (2007). Approximately normal tests for equal predictive accuracy in nested models. Journal of Econometrics, 138, 291-311.

Colombo, V. (2013). Economic policy uncertainty in the US: Does it matter for the Euro area? Economics Letters, 121(1), 39-42.

Corsi, F. (2009). A simple approximate long-memory model of realized volatility. Journal of Financial Econometrics, 7, 174-196.

Davis, S.J. (2017). Regulatory complexity and policy uncertainty: headwinds of our own making. Working Paper Series, Hoover Institution. https://www.hoover.org/sites/default/files/steve_davis_regulatory_complexity_a nd_policy_uncertainty_headwinds_of_own_making_january_2017.pdf

Degiannakis, S, \& Filis, G. (2017). Forecasting oil price realized volatility using information channels from other asset classes. Journal of International Money and Finance, 76, 28-49.

Diebold, F.X., \& Mariano, R. S. (1995). Comparing predictive accuracy. Journal of Business and Economic Statistics, 13, 253-263.

Hansen, P.R. (2005). A Test for Superior Predictive Ability. Journal of Business and Economic Statistics, 23, 365-380.

Hansen, P.R., Lunde, A., \& Nason, J.M. (2011). The model confidence set. Econometrica, 79(2), 453-497.

Hassett, A.K. \& Sullivan, W.J. (2016). Policy uncertainty and the economy. Working Paper, American Enterprise Institute.

Jurado, K., Ludvigson, S.C., \& Ng, S. (2015). Measuring uncertainty. The American Economic Review, 105(3), 1177-1216.

Kang, W., Lee, K. \& Ratti, R.A. (2014). Economic policy uncertainty and firm-level investment. Journal of Macroeconomics, 39, 42-53.

Kang, W. \& Ratti, R.A. (2013). Oil shocks, policy uncertainty and stock market return. Journal of International Financial Markets, Institutions and Money, 26, 305-318

Karnizova, L. \& Li, J.C. (2014). Economic policy uncertainty, financial markets and probability of US recessions. Economics Letters, 125(2), 261-265. 
Ko, J.H., \& Lee, C.M. (2015). International economic policy uncertainty and stock prices: Wavelet approach. Economics Letters, 134, 118-122.

Leduc, S., \& Liu, Z. (2016). Uncertainty shocks are aggregate demand shocks. Journal of Monetary Economics, 82, 20-35.

Liu, L. \& Zhang, T. (2015). Economic policy uncertainty and stock market volatility. Finance Research Letters, 15, 99-105.

Marcellino, M., Stock, J. H., \& Watson, M. W. (2003). Macroeconomic forecasting in the euro area: Country specific versus area-wide information. European Economic Review, 47(1), 1-18.

Marcus, A.A. (1981). Policy uncertainty and technological innovation. Academy of Management Review, 6(3), 443-448.

New York Times. (2016). An index of uncertainty surges after 'Brexit', 29/06/2016. https://www.nytimes.com/2016/07/01/upshot/an-index-of-uncertainty-surgesafter-brexit.html?_r=0.

Pindyck, R.S. (1990). Irreversibility, uncertainty, and investment. National Bureau of Economic Research, W3307.

Scotti, C. (2016). Surprise and uncertainty indexes: Real-time aggregation of realactivity macrosurprises. Journal of Monetary Economics, 82(C), 1-19.

Silva, E. S., \& Hassani, H. (2015). On the use of singular spectrum analysis for forecasting US trade before, during and after the 2008 recession. International Economics, 141, 34-49.

Strobel, J. (2015). On the different approaches of measuring uncertainty shocks. Economics Letters, 134, 69-72.

Visco, I. (2017). Financial Market Volatility and Global Policy Uncertainty: a Conundrum, Istituto Affari Internazionali, Major Challenges for Global Macroeconomic Stability - The Role of the G7, 27/03/2017. http://www.iai.it/sites/default/files/visco-dinner_address_170327.pdf.

Wang, Y., Zhang, B., Diao, X., \& Wu, C. (2015). Commodity price changes and the predictability of economic policy uncertainty. Economics Letters, 127, 39-42. 


\section{Tables}

\begin{tabular}{|c|c|c|c|}
\hline Name & Acronym & Description & Source \\
\hline \multicolumn{4}{|c|}{ Variable to be forecasted } \\
\hline $\begin{array}{l}\text { European Economic } \\
\text { Policy Uncertainty } \\
\text { Index }\end{array}$ & EPU & $\begin{array}{l}\text { Proxy for the European } \\
\text { macroeconomic volatility }\end{array}$ & Baker et al. (2016) \\
\hline \multicolumn{4}{|c|}{ European related exogenous variables } \\
\hline FTSE100 index & FT & $\begin{array}{l}\text { Tick-by-tick data of the } \\
\text { front-month futures prices }\end{array}$ & TickData \\
\hline Euro Stoxx 50 index & $\mathrm{XX}$ & $\begin{array}{l}\text { Tick-by-tick data of the } \\
\text { front-month futures prices }\end{array}$ & TickData \\
\hline $\begin{array}{l}\text { GBP/USD exchange } \\
\text { rate }\end{array}$ & $\mathrm{BP}$ & $\begin{array}{l}\text { Tick-by-tick data of the } \\
\text { front-month futures prices }\end{array}$ & TickData \\
\hline $\begin{array}{l}\text { EUR/USD exchange } \\
\text { rate }\end{array}$ & $\mathrm{EC}$ & $\begin{array}{l}\text { Tick-by-tick data of the } \\
\text { front-month futures prices }\end{array}$ & TickData \\
\hline \multicolumn{4}{|c|}{ Global related exogenous variables } \\
\hline Brent Crude Oil & OP & $\begin{array}{l}\text { Tick-by-tick data of the } \\
\text { front-month futures prices }\end{array}$ & TickData \\
\hline S\&P500 index & SP & $\begin{array}{l}\text { Tick-by-tick data of the } \\
\text { front-month futures prices }\end{array}$ & TickData \\
\hline US 10yr T-bills & TY & $\begin{array}{l}\text { Tick-by-tick data of the } \\
\text { front-month futures prices }\end{array}$ & TickData \\
\hline $\begin{array}{l}\text { Global Economic Policy } \\
\text { Uncertainty Index }\end{array}$ & GEPU & $\begin{array}{l}\text { Proxy for the Global } \\
\text { macroeconomic volatility }\end{array}$ & Baker et al. (2016) \\
\hline
\end{tabular}


Table 2: Descriptive statistics (August, 2003 - August, 2015).

\begin{tabular}{lccccccccc}
\hline & EPU & \multicolumn{1}{c}{ FT } & XX & \multicolumn{1}{c}{ BP } & \multicolumn{1}{c}{ EC } & \multicolumn{1}{c}{ CO } & \multicolumn{1}{l}{ SP } & \multicolumn{1}{c}{ TY } & \multicolumn{1}{c}{ GEPU } \\
\cline { 2 - 9 } Mean & 1.3603 & 0.1656 & 0.2043 & 0.0901 & 0.0946 & 0.2834 & 0.1550 & 0.0732 & 1.0557 \\
Maximum & 3.0460 & 0.5919 & 0.6183 & 0.2999 & 0.2492 & 0.9243 & 0.5914 & 0.2842 & 2.1705 \\
Minimum & 0.4769 & 0.0525 & 0.0699 & 0.0292 & 0.0349 & 0.0667 & 0.0443 & 0.0255 & 0.5350 \\
Std. Dev. & 0.5350 & 0.0890 & 0.0909 & 0.0388 & 0.0384 & 0.1403 & 0.0896 & 0.0441 & 0.3863 \\
Skewness & 0.5536 & 2.0757 & 1.5349 & 1.9950 & 1.4907 & 1.5792 & 1.9947 & 1.9427 & 0.8075 \\
Kurtosis & 2.7479 & 8.5856 & 6.1548 & 9.6136 & 5.6034 & 6.5610 & 8.3326 & 7.4817 & 3.0385 \\
Jarque-Bera & 7.7904 & 292.6188 & 117.0672 & 360.4404 & 94.6537 & 136.8825 & 267.9607 & 212.5586 & 15.7655 \\
Probability & 0.0203 & 0.0000 & 0.0000 & 0.0000 & 0.0000 & 0.0000 & 0.0000 & 0.0000 & 0.0004
\end{tabular}

Note: EPU $=$ European economic policy uncertainty, FT $=$ FTSE100 volatility, $\mathrm{XX}=$ EUROSTOXX 50 volatility, $\mathrm{BP}=$ GBP/USD volatility, EC = EUR/USD volatility, $\mathrm{CO}=$ Brent crude oil price volatility, SP = S\&P500 volatility, TY = US Tbill volatility, GEPU = Global economic policy uncertainty. 
Table 3: Forecast evaluation of monthly European Economic Policy Uncertainty based on the MSPE. Evaluation period: December, 2011 - August, 2015.

\begin{tabular}{|c|c|c|c|c|c|c|c|c|c|c|c|}
\hline $\begin{array}{c}\text { Forecasting } \\
\text { Horizon }\end{array}$ & RW & $\mathrm{AR}(1)$ & HAR & $\begin{array}{c}\text { HAR- } \\
\text { FT }\end{array}$ & $\begin{array}{c}\text { HAR- } \\
\text { XX }\end{array}$ & $\begin{array}{c}\text { HAR- } \\
\text { BP }\end{array}$ & $\begin{array}{c}\text { HAR- } \\
\text { EC }\end{array}$ & $\begin{array}{c}\text { HAR- } \\
\mathrm{CO}\end{array}$ & $\begin{array}{c}\text { HAR- } \\
\text { SP }\end{array}$ & $\begin{array}{c}\text { HAR- } \\
\text { TY }\end{array}$ & $\begin{array}{l}\text { HAR- } \\
\text { GEPU }\end{array}$ \\
\hline & & \multicolumn{10}{|c|}{ MSPE ratio } \\
\hline 1 & 5144.09 & 0.1858 & 0.1580 & 0.1470 & 0.1566 & 0.2016 & 0.2654 & 0.1746 & 0.1586 & 0.1432 & $\mathbf{0 . 1 7 3 7}$ \\
\hline 2 & 4880.82 & 0.3001 & 0.2205 & 0.2203 & 0.2141 & 0.3063 & 0.4036 & 0.2629 & 0.2281 & 0.2147 & 0.2261 \\
\hline 3 & 4777.60 & 0.3802 & 0.2453 & 0.2328 & 0.2287 & 0.3774 & 0.4984 & 0.3109 & 0.2411 & 0.2536 & 0.2190 \\
\hline 4 & 4775.07 & 0.4612 & 0.2574 & 0.2474 & 0.2453 & 0.4084 & 0.5960 & 0.3560 & 0.2409 & 0.2508 & 0.1999 \\
\hline 5 & 4832.12 & 0.5330 & 0.2574 & 0.2422 & 0.2306 & 0.4557 & 0.7216 & 0.3893 & 0.2313 & 0.2437 & 0.1736 \\
\hline 6 & 4714.48 & 0.5867 & 0.2785 & 0.2535 & 0.2341 & 0.5632 & 0.9475 & 0.4512 & 0.2497 & 0.2622 & 0.1855 \\
\hline 7 & 4482.25 & 0.6501 & 0.3457 & 0.2887 & 0.2624 & 0.7205 & 1.2933 & 0.5824 & 0.2952 & 0.2840 & 0.2311 \\
\hline 8 & 4165.94 & 0.7047 & 0.4267 & 0.3270 & 0.2966 & 0.9697 & 1.7610 & 0.7454 & 0.3489 & 0.3179 & 0.2818 \\
\hline 9 & 4067.91 & 0.7407 & 0.4676 & 0.3377 & 0.3066 & 1.1812 & 2.2674 & 0.8339 & 0.3829 & 0.3537 & 0.2884 \\
\hline 10 & 4187.19 & 0.7898 & 0.4853 & 0.3356 & 0.2957 & 1.2525 & 2.6567 & 0.8792 & 0.3692 & 0.3471 & 0.2523 \\
\hline 11 & 4066.16 & 0.8186 & 0.5677 & 0.4048 & 0.3418 & 1.6345 & 3.5655 & 1.0392 & 0.4380 & 0.4033 & 0.2899 \\
\hline 12 & 3878.64 & 0.8550 & 0.7146 & 0.5075 & 0.4188 & 2.3234 & 5.1534 & 1.3069 & 0.5516 & 0.5215 & 0.3369 \\
\hline
\end{tabular}

Note: All MSPE ratios have been normalized relative to the no-change forecast. The RW (Random-Walk) model values refer to the actual MSPE. Bold face values denote that the model is included in the set of the best models according to the MCS test. FT = FTSE100 volatility, XX = EUROSTOXX 50 volatility, BP = GBP/USD volatility, EC = EUR/USD volatility, $\mathrm{CO}=$ Brent crude oil price volatility, $\mathrm{SP}=\mathrm{S} \& \mathrm{P} 500$ volatility, $\mathrm{TY}=\mathrm{US}$ T-bill volatility, GEPU $=$ Global economic policy uncertainty. 
Table 4: Forecast evaluation of monthly European Economic Policy Uncertainty based on the MAPPE. Evaluation period: December, 2011 - August, 2015.

\begin{tabular}{|c|c|c|c|c|c|c|c|c|c|c|c|}
\hline $\begin{array}{c}\text { Forecasting } \\
\text { Horizon }\end{array}$ & RW & $\operatorname{AR}(1)$ & HAR & $\begin{array}{l}\text { HAR- } \\
\text { FT }\end{array}$ & $\begin{array}{l}\text { HAR- } \\
\text { XX }\end{array}$ & $\begin{array}{c}\text { HAR- } \\
\text { BP }\end{array}$ & $\begin{array}{l}\text { HAR- } \\
\text { EC }\end{array}$ & $\begin{array}{c}\text { HAR- } \\
\mathrm{CO}\end{array}$ & $\begin{array}{l}\text { HAR- } \\
\text { SP }\end{array}$ & $\begin{array}{l}\text { HAR- } \\
\text { TY }\end{array}$ & $\begin{array}{l}\text { HAR- } \\
\text { GEPU }\end{array}$ \\
\hline & & \multicolumn{10}{|c|}{ MAPPE ratio } \\
\hline 1 & $30.89 \%$ & 0.4494 & 0.4409 & 0.4188 & 0.4237 & 0.4938 & 0.5399 & 0.4690 & 0.4194 & 0.4299 & 0.4543 \\
\hline 2 & $30.17 \%$ & 0.5414 & 0.5202 & 0.5232 & 0.5155 & 0.5804 & 0.6698 & 0.5592 & 0.5309 & 0.5139 & 0.5174 \\
\hline 3 & $29.92 \%$ & 0.5649 & 0.5819 & 0.5524 & 0.5466 & 0.6657 & 0.7547 & 0.6588 & 0.5644 & 0.5708 & 0.5178 \\
\hline 4 & $29.78 \%$ & 0.6584 & 0.5896 & 0.5584 & 0.5505 & 0.7082 & 0.8071 & 0.7077 & 0.5642 & 0.5734 & 0.5091 \\
\hline 5 & $29.75 \%$ & 0.6947 & 0.6174 & 0.5556 & 0.5523 & 0.7694 & 0.9382 & 0.7903 & 0.5801 & 0.5674 & 0.4967 \\
\hline 6 & $29.44 \%$ & 0.7630 & 0.6388 & 0.6009 & 0.5763 & 0.8166 & 1.0901 & 0.8125 & 0.6103 & 0.6040 & 0.5124 \\
\hline 7 & $29.00 \%$ & 0.7672 & 0.7061 & 0.6352 & 0.5929 & 0.9329 & 1.2716 & 0.9557 & 0.6419 & 0.6250 & 0.5699 \\
\hline 8 & $28.50 \%$ & 0.8069 & 0.7838 & 0.6899 & 0.6575 & 1.0714 & 1.4713 & 1.0699 & 0.7049 & 0.6731 & 0.6145 \\
\hline 9 & $28.18 \%$ & 0.8548 & 0.8130 & 0.6922 & 0.6511 & 1.1866 & 1.6609 & 1.1552 & 0.7236 & 0.7003 & 0.6108 \\
\hline 10 & $28.36 \%$ & 0.8675 & 0.8490 & 0.6953 & 0.6580 & 1.2323 & 1.8015 & 1.1949 & 0.7349 & 0.7088 & 0.6029 \\
\hline 11 & $27.99 \%$ & 0.8734 & 0.8980 & 0.7592 & 0.6989 & 1.3617 & 2.0713 & 1.2905 & 0.7937 & 0.7525 & 0.6520 \\
\hline 12 & $27.55 \%$ & 0.9139 & 1.0268 & 0.8414 & 0.7723 & 1.6211 & 2.4978 & 1.4330 & 0.8882 & 0.8495 & 0.6965 \\
\hline
\end{tabular}

Note: All MAPPE ratios have been normalized relative to the no-change forecast. The RW (Random-Walk) model values refer to the actual MAPPE. Bold face values denote that the model is included in the set of the best models according to the MCS test. FT = FTSE100 volatility, XX $=$ EUROSTOXX 50 volatility, $\mathrm{BP}=\mathrm{GBP} / \mathrm{USD}$ volatility, $\mathrm{EC}=\mathrm{EUR} / \mathrm{USD}$ volatility, $\mathrm{CO}=\mathrm{Brent}$ crude oil price volatility, $\mathrm{SP}=\mathrm{S} \& \mathrm{P} 500$ volatility, TY = US T-bill volatility, GEPU = Global economic policy uncertainty. 
Table 5: Success ratio of the best competing models. Evaluation period: 2011.12-2015.8.

\begin{tabular}{cccccc}
\hline $\begin{array}{c}\text { Forecasting } \\
\text { Horizon }\end{array}$ & $\begin{array}{c}\text { HAR- } \\
\text { FT }\end{array}$ & $\begin{array}{c}\text { HAR- } \\
\text { XX }\end{array}$ & $\begin{array}{c}\text { HAR- } \\
\text { SP }\end{array}$ & $\begin{array}{c}\text { HAR- } \\
\text { TY }\end{array}$ & $\begin{array}{c}\text { HAR- } \\
\text { GEPU }\end{array}$ \\
\hline 1 & 0.6364 & 0.6364 & 0.6970 & 0.6667 & 0.5152 \\
2 & 0.5758 & 0.5758 & 0.6061 & 0.5152 & 0.6061 \\
3 & 0.5455 & 0.5455 & 0.6061 & 0.5455 & 0.6364 \\
4 & 0.6061 & 0.6061 & 0.6061 & 0.6061 & 0.6061 \\
5 & 0.6364 & 0.6061 & 0.6061 & 0.6364 & 0.6061 \\
6 & 0.5758 & 0.5758 & 0.6364 & 0.5758 & 0.6667 \\
7 & 0.6061 & 0.6667 & 0.6364 & 0.5455 & 0.6667 \\
8 & 0.6667 & 0.6364 & 0.6667 & 0.6667 & 0.6667 \\
9 & 0.6667 & 0.6667 & 0.7273 & 0.6364 & 0.7879 \\
10 & 0.6364 & 0.6364 & 0.6667 & 0.6970 & 0.7273 \\
11 & 0.6364 & 0.6970 & 0.6364 & 0.6364 & 0.6970 \\
12 & 0.6667 & 0.6970 & 0.6970 & 0.6364 & 0.6970 \\
\hline $\begin{array}{l}\text { Note: FT = FTSE100 volatility, XX = EUROSTOXX 50 volatility, SP = } \\
\text { S\&P500 volatility, TY = US T-bill volatility, GEPU = Global economic } \\
\text { policy uncertainty. }\end{array}$ & & & & \\
\hline
\end{tabular}


Table 6: Alternative measures of asset volatility and financial uncertainty. Evaluation period: December, 2011 - August, 2015.

\begin{tabular}{|c|c|c|c|c|c|c|c|c|c|}
\hline $\begin{array}{c}\text { Forecasting } \\
\text { Horizon }\end{array}$ & RW & $\begin{array}{c}\text { HAR- } \\
\text { VFTSE }\end{array}$ & $\begin{array}{c}\text { HAR- } \\
\text { VSTOXX }\end{array}$ & $\begin{array}{l}\text { HAR- } \\
\text { VBP }\end{array}$ & $\begin{array}{l}\text { HAR- } \\
\text { VEC }\end{array}$ & $\begin{array}{c}\text { HAR- } \\
\text { VBRENT }\end{array}$ & $\begin{array}{l}\text { HAR- } \\
\text { OVX }\end{array}$ & $\begin{array}{c}\text { HAR- } \\
\text { VIX }\end{array}$ & $\begin{array}{c}\text { HAR- } \\
\text { FINUNC }\end{array}$ \\
\hline & & \multicolumn{8}{|c|}{ MSPE ratio } \\
\hline 1 & 5144.09 & 0.1582 & 0.1340 & 0.1566 & 0.1962 & 0.1853 & 0.1923 & 0.1359 & 0.1641 \\
\hline 2 & 4880.82 & 0.2551 & 0.2109 & 0.2429 & 0.3797 & 0.2682 & 0.2936 & 0.2162 & 0.2459 \\
\hline 3 & 4777.60 & 0.2606 & 0.2343 & 0.2860 & 0.4854 & 0.3084 & 0.3688 & 0.2573 & 0.2932 \\
\hline 4 & 4775.07 & 0.2746 & 0.2616 & 0.2890 & 0.5812 & 0.3424 & 0.4349 & 0.2596 & 0.3462 \\
\hline 5 & 4832.12 & 0.2834 & 0.2656 & 0.2801 & 0.6782 & 0.3547 & 0.4828 & 0.2603 & 0.3888 \\
\hline 6 & 4714.48 & 0.2848 & 0.2485 & 0.2940 & 0.8329 & 0.4077 & 0.5544 & 0.2763 & 0.4471 \\
\hline 7 & 4482.25 & 0.3288 & 0.2596 & 0.3382 & 1.0904 & 0.5414 & 0.6745 & 0.3393 & 0.5539 \\
\hline 8 & 4165.94 & 0.3650 & 0.2660 & 0.3857 & 1.4590 & 0.7327 & 0.8374 & 0.3922 & 0.6577 \\
\hline 9 & 4067.91 & 0.3655 & 0.2506 & 0.4176 & 1.8105 & 0.8479 & 0.9537 & 0.4254 & 0.7475 \\
\hline 10 & 4187.19 & 0.3435 & 0.2527 & 0.4570 & 2.1872 & 0.9308 & 1.0733 & 0.4584 & 0.8843 \\
\hline 11 & 4066.16 & 0.4045 & 0.2888 & 0.5564 & 2.9442 & 1.1313 & 1.2549 & 0.5320 & 1.0896 \\
\hline 12 & 3878.64 & 0.5329 & 0.3842 & 0.7276 & 4.2362 & 1.4660 & 1.5449 & 0.6789 & 1.4049 \\
\hline
\end{tabular}

Note: All MSPE ratios have been normalized relative to the no-change forecast. VFTSE=implied volatility index of the FTSE100, VSTOXX = implied volatility index of Euro Stoxx 50, VBP = implied volatility index of the GBP/USD exchange rate, VEC $=$ implied volatility index of the EUR/USD exchange rate, VBRENT $=$ implied volatility index of the Brent crude oil, OVX $=$ implied volatility index of the WTI crude oil, VIX = implied volatility index of the S\&P500 and FINUNC = Jurado's et al. (2015) Financial Uncertainty index. 
Table 7: Alternative measures of asset volatility and financial uncertainty. Evaluation period: December, 2011 - August, 2015.

\begin{tabular}{|c|c|c|c|c|c|c|c|c|c|}
\hline $\begin{array}{c}\text { Forecasting } \\
\text { Horizon }\end{array}$ & RW & $\begin{array}{c}\text { HAR- } \\
\text { VFTSE }\end{array}$ & $\begin{array}{c}\text { HAR- } \\
\text { VSTOXX }\end{array}$ & $\begin{array}{l}\text { HAR- } \\
\text { VBP }\end{array}$ & $\begin{array}{l}\text { HAR- } \\
\text { VEC }\end{array}$ & $\begin{array}{c}\text { HAR- } \\
\text { VBRENT }\end{array}$ & $\begin{array}{l}\text { HAR- } \\
\text { OVX }\end{array}$ & $\begin{array}{c}\text { HAR- } \\
\text { VIX }\end{array}$ & $\begin{array}{c}\text { HAR- } \\
\text { FINUNC }\end{array}$ \\
\hline & & \multicolumn{8}{|c|}{ MAPPE ratio } \\
\hline 1 & $30.89 \%$ & 0.4132 & 0.3719 & 0.4497 & 0.4745 & 0.4823 & 0.4979 & 0.3963 & 0.4553 \\
\hline 2 & $30.17 \%$ & 0.5642 & 0.5176 & 0.5385 & 0.6387 & 0.5652 & 0.6239 & 0.5532 & 0.5620 \\
\hline 3 & $29.92 \%$ & 0.5710 & 0.5424 & 0.5796 & 0.7196 & 0.6397 & 0.7254 & 0.5916 & 0.6090 \\
\hline 4 & $29.78 \%$ & 0.5857 & 0.5717 & 0.5927 & 0.7776 & 0.6607 & 0.8192 & 0.5968 & 0.6501 \\
\hline 5 & $29.75 \%$ & 0.5908 & 0.5798 & 0.6093 & 0.8799 & 0.7184 & 0.8580 & 0.6107 & 0.7087 \\
\hline 6 & $29.44 \%$ & 0.6216 & 0.5687 & 0.6331 & 0.9970 & 0.7705 & 0.9017 & 0.6528 & 0.7835 \\
\hline 7 & $29.00 \%$ & 0.6643 & 0.5750 & 0.6672 & 1.1574 & 0.9044 & 1.0045 & 0.6974 & 0.8530 \\
\hline 8 & $28.50 \%$ & 0.7170 & 0.6087 & 0.7204 & 1.3178 & 0.9970 & 1.1155 & 0.7586 & 0.9243 \\
\hline 9 & $28.18 \%$ & 0.7115 & 0.5954 & 0.7624 & 1.4616 & 1.0806 & 1.1961 & 0.7826 & 0.9959 \\
\hline 10 & $28.36 \%$ & 0.6959 & 0.5925 & 0.7969 & 1.5892 & 1.1553 & 1.3010 & 0.8100 & 1.0842 \\
\hline 11 & $27.99 \%$ & 0.7500 & 0.6232 & 0.8400 & 1.8547 & 1.2564 & 1.4425 & 0.8734 & 1.1910 \\
\hline 12 & $27.55 \%$ & 0.8572 & 0.7172 & 0.9771 & 2.2065 & 1.4312 & 1.6099 & 0.9890 & 1.3866 \\
\hline
\end{tabular}

Note: All MAPPE ratios have been normalized relative to the no-change forecast. VFTSE=implied volatility index of the FTSE100, VSTOXX = implied volatility index of Euro Stoxx 50, VBP = implied volatility index of the GBP/USD exchange rate, VEC $=$ implied volatility index of the EUR/USD exchange rate, VBRENT $=$ implied volatility index of the Brent crude oil, OVX $=$ implied volatility index of the WTI crude oil, VIX = implied volatility index of the S\&P500 and FINUNC = Jurado's et al. (2015) Financial Uncertainty index. 
Table 8: Economic policy uncertainty of individual European countries and the US. Evaluation period: December, 2011 - August, 2015.

\begin{tabular}{ccccccccccc}
\hline \multirow{2}{*}{$\begin{array}{c}\text { Forecasting } \\
\text { Horizon }\end{array}$} & RW & $\begin{array}{c}\text { HAR- } \\
\text { EPU- } \\
\text { US }\end{array}$ & $\begin{array}{c}\text { HAR- } \\
\text { EPU- } \\
\text { UK }\end{array}$ & $\begin{array}{c}\text { HAR- } \\
\text { EPU- } \\
\text { FRA }\end{array}$ & $\begin{array}{c}\text { HAR- } \\
\text { EPU- } \\
\text { GER }\end{array}$ & $\begin{array}{c}\text { HAR- } \\
\text { EPU- } \\
\text { IRE }\end{array}$ & $\begin{array}{c}\text { HAR- } \\
\text { EPU- } \\
\text { ITA }\end{array}$ & $\begin{array}{c}\text { HAR- } \\
\text { EPU- } \\
\text { NL }\end{array}$ & $\begin{array}{c}\text { HAR- } \\
\text { EPU- } \\
\text { SPA }\end{array}$ & $\begin{array}{c}\text { HAR- } \\
\text { EPU- } \\
\text { SWE }\end{array}$ \\
\hline & & & & & & & \\
2 & 5144.09 & 0.1698 & 0.1532 & 0.1630 & 0.1626 & 0.1613 & 0.1526 & 0.1588 & 0.1825 & 0.1814 \\
3 & 4880.82 & 0.2390 & 0.2114 & 0.2378 & 0.2347 & 0.2158 & 0.1993 & 0.2203 & 0.3055 & 0.2501 \\
4 & 4777.60 & 0.2371 & 0.2337 & 0.2713 & 0.2784 & 0.2339 & 0.2108 & 0.2418 & 0.3317 & 0.2899 \\
5 & 4775.07 & 0.2353 & 0.2471 & 0.2844 & 0.3196 & 0.2212 & 0.2288 & 0.2454 & 0.3681 & 0.3093 \\
6 & 4832.12 & 0.2430 & 0.2648 & 0.2822 & 0.3440 & 0.2176 & 0.2619 & 0.2514 & 0.3896 & 0.3282 \\
7 & 4714.48 & 0.2584 & 0.2826 & 0.3153 & 0.3964 & 0.2404 & 0.3188 & 0.2789 & 0.4391 & 0.3492 \\
8 & 4482.25 & 0.2912 & 0.3175 & 0.3540 & 0.5265 & 0.2758 & 0.4266 & 0.3636 & 0.5405 & 0.4078 \\
9 & 4165.94 & 0.3128 & 0.3442 & 0.3887 & 0.6894 & 0.3073 & 0.5716 & 0.4696 & 0.6638 & 0.4789 \\
10 & 4067.91 & 0.3041 & 0.3538 & 0.4138 & 0.7959 & 0.3248 & 0.6546 & 0.5267 & 0.7732 & 0.5163 \\
11 & 4187.19 & 0.3209 & 0.3634 & 0.4196 & 0.9279 & 0.3182 & 0.8220 & 0.5275 & 0.8772 & 0.5506 \\
12 & 4066.16 & 0.3456 & 0.4059 & 0.4633 & 1.2004 & 0.3661 & 1.0694 & 0.6517 & 1.1097 & 0.6238 \\
& 3878.64 & 0.3689 & 0.4671 & 0.5457 & 1.5716 & 0.4352 & 1.4209 & 0.8494 & 1.5570 & 0.7758 \\
\hline
\end{tabular}

Note: All MSPE ratios have been normalized relative to the no-change forecast. The RW (Random-Walk) model values refer to the actual MSPE. 
Table 9: Economic policy uncertainty of individual European countries and the US. Evaluation period: December, 2011 - August, 2015.

\begin{tabular}{ccccccccccc}
\hline \multirow{2}{*}{$\begin{array}{c}\text { Forecasting } \\
\text { Horizon }\end{array}$} & RW & $\begin{array}{c}\text { HAR- } \\
\text { EPU- } \\
\text { US }\end{array}$ & $\begin{array}{c}\text { HAR- } \\
\text { EPU- } \\
\text { UK }\end{array}$ & $\begin{array}{c}\text { HAR- } \\
\text { EPU- } \\
\text { FRA }\end{array}$ & $\begin{array}{c}\text { HAR- } \\
\text { EPU- } \\
\text { GER }\end{array}$ & $\begin{array}{c}\text { HAR- } \\
\text { EPU- } \\
\text { IRE }\end{array}$ & $\begin{array}{c}\text { HAR- } \\
\text { EPU- } \\
\text { ITA }\end{array}$ & $\begin{array}{c}\text { HAR- } \\
\text { EPU- } \\
\text { NL }\end{array}$ & $\begin{array}{c}\text { HAR- } \\
\text { EPU- } \\
\text { SPA }\end{array}$ & $\begin{array}{c}\text { HAR- } \\
\text { EPU- } \\
\text { SWE }\end{array}$ \\
\hline & & & & \multicolumn{1}{c}{ ratio } \\
2 & $30.89 \%$ & 0.4244 & 0.4314 & 0.4599 & 0.4526 & 0.4586 & 0.4210 & 0.4478 & 0.4566 & 0.4735 \\
3 & $30.17 \%$ & 0.4996 & 0.4902 & 0.5775 & 0.5678 & 0.5147 & 0.4674 & 0.5206 & 0.6049 & 0.5540 \\
4 & $29.92 \%$ & 0.4883 & 0.5321 & 0.6279 & 0.6253 & 0.5469 & 0.5047 & 0.5582 & 0.6430 & 0.6204 \\
5 & $29.78 \%$ & 0.5066 & 0.5539 & 0.6377 & 0.6658 & 0.5654 & 0.5189 & 0.5555 & 0.6994 & 0.6724 \\
6 & $29.75 \%$ & 0.4981 & 0.5867 & 0.6636 & 0.7349 & 0.5563 & 0.5888 & 0.6000 & 0.7436 & 0.7155 \\
7 & $29.44 \%$ & 0.5436 & 0.6171 & 0.6966 & 0.7643 & 0.5986 & 0.6360 & 0.6252 & 0.8093 & 0.7274 \\
8 & $29.00 \%$ & 0.5818 & 0.6629 & 0.7308 & 0.8819 & 0.6337 & 0.7374 & 0.7134 & 0.8978 & 0.8008 \\
9 & $28.50 \%$ & 0.6007 & 0.6773 & 0.7551 & 1.0180 & 0.6744 & 0.8399 & 0.7918 & 0.9636 & 0.8584 \\
10 & $28.18 \%$ & 0.5945 & 0.7014 & 0.7903 & 1.1145 & 0.6798 & 0.9033 & 0.8477 & 1.0451 & 0.9021 \\
11 & $28.36 \%$ & 0.6149 & 0.7103 & 0.8005 & 1.2268 & 0.6804 & 1.0001 & 0.8684 & 1.1073 & 0.9147 \\
12 & $27.99 \%$ & 0.6170 & 0.7661 & 0.8127 & 1.4216 & 0.7205 & 1.1238 & 0.9564 & 1.2682 & 0.9418 \\
\hline
\end{tabular}

Note: All MAPPE ratios have been normalized relative to the no-change forecast. The RW (Random-Walk) model values refer to the actual MAPPE. 
Table 10: Incorporating asymmetries in the HAR-X model. Evaluation period: December, 2011 - August, 2015.

\begin{tabular}{ccccccccc}
\hline $\begin{array}{c}\text { Forecasting } \\
\text { Horizon }\end{array}$ & $\begin{array}{c}\text { HAR- } \\
\text { FT }\end{array}$ & $\begin{array}{c}\text { HAR- } \\
\text { XX }\end{array}$ & $\begin{array}{c}\text { HAR- } \\
\text { BP }\end{array}$ & $\begin{array}{c}\text { HAR- } \\
\text { EC }\end{array}$ & $\begin{array}{c}\text { HAR- } \\
\text { CO }\end{array}$ & $\begin{array}{c}\text { HAR- } \\
\text { SP }\end{array}$ & $\begin{array}{c}\text { HAR- } \\
\text { TY }\end{array}$ & $\begin{array}{c}\text { HAR- } \\
\text { GEPU }\end{array}$ \\
\hline & & & \multicolumn{7}{c}{ MSPE ratio } \\
1 & 1.0351 & 1.0116 & 1.0690 & 1.0283 & 1.0653 & 1.0557 & 1.1864 & 1.1251 \\
2 & 1.1131 & 0.9815 & 1.1268 & 0.9590 & 1.0221 & 0.9059 & 1.4037 & 1.1855 \\
3 & 1.1366 & 1.0040 & 1.0675 & 1.0711 & 1.0103 & 0.8441 & 1.7126 & 1.1801 \\
4 & 1.1202 & 0.9780 & 1.0351 & 1.1307 & 0.9808 & 0.8591 & 2.1520 & 1.1999 \\
5 & 1.0795 & 0.9441 & 0.9997 & 1.1357 & 0.9957 & 0.8438 & 2.5009 & 1.2399 \\
6 & 1.0486 & 0.9088 & 1.0153 & 1.1139 & 0.9733 & 0.8044 & 2.3326 & 1.1576 \\
7 & 1.0801 & 0.9640 & 0.9880 & 1.1014 & 0.9836 & 0.7733 & 2.3641 & 1.0763 \\
8 & 1.1327 & 1.0139 & 1.0206 & 1.0839 & 1.0405 & 0.6774 & 2.5898 & 1.0553 \\
9 & 1.1375 & 0.9978 & 1.0307 & 1.1096 & 1.3096 & 0.6412 & 2.5375 & 1.1391 \\
10 & 1.1084 & 1.0211 & 1.0084 & 1.1723 & 1.6661 & 0.6773 & 2.7554 & 1.2766 \\
11 & 1.1301 & 1.0717 & 0.9702 & 1.2091 & 2.0634 & 0.6493 & 2.6034 & 1.3093 \\
12 & 1.1469 & 1.0972 & 0.9349 & 1.2434 & 2.3469 & 0.6133 & 2.5446 & 1.2550
\end{tabular}

Note: All MSPE ratios have been normalized relative to the equivalent symmetric HAR-X model from Table 3. A value below 1 suggests that the asymmetric HAR-X model provides predictive gains relative to the equivalent symmetric HAR-X model. FT = FTSE100 volatility, $\mathrm{XX}=$ EUROSTOXX 50 volatility, $\mathrm{BP}=\mathrm{GBP} / \mathrm{USD}$ volatility, $\mathrm{EC}=\mathrm{EUR} / \mathrm{USD}$ volatility, $\mathrm{CO}=$ Brent crude oil price volatility, $\mathrm{SP}=\mathrm{S} \& \mathrm{P} 500$ volatility, $\mathrm{TY}=\mathrm{US} \mathrm{T}-$ bill volatility, GEPU = Global economic policy uncertainty. 
Table 11: Incorporating asymmetries in the HAR-X model. Evaluation period: December, 2011 August, 2015.

\begin{tabular}{ccccccccc}
\hline $\begin{array}{c}\text { Forecasting } \\
\text { Horizon }\end{array}$ & $\begin{array}{c}\text { HAR- } \\
\text { FT }\end{array}$ & $\begin{array}{c}\text { HAR- } \\
\text { XX }\end{array}$ & $\begin{array}{c}\text { HAR- } \\
\text { BP }\end{array}$ & $\begin{array}{c}\text { HAR- } \\
\text { EC }\end{array}$ & $\begin{array}{c}\text { HAR- } \\
\text { CO }\end{array}$ & $\begin{array}{c}\text { HAR- } \\
\text { SP }\end{array}$ & $\begin{array}{c}\text { HAR- } \\
\text { TY }\end{array}$ & $\begin{array}{c}\text { HAR- } \\
\text { GEPU }\end{array}$ \\
\cline { 2 - 9 } 1 & & & & & & \\
2 & 1.0336 & 0.9987 & 1.0606 & 1.0339 & 1.0418 & 1.0384 & 1.0740 & 1.0673 \\
3 & 1.0484 & 0.9838 & 1.0736 & 0.9738 & 1.0438 & 0.9466 & 1.2135 & 1.0696 \\
4 & 1.0633 & 0.9618 & 1.0373 & 0.9936 & 1.0066 & 0.9156 & 1.2816 & 1.0825 \\
5 & 1.0667 & 0.9625 & 1.0218 & 1.0188 & 0.9900 & 0.9328 & 1.3320 & 1.0683 \\
6 & 1.0598 & 0.9511 & 1.0223 & 1.0299 & 0.9569 & 0.8596 & 1.3250 & 1.1045 \\
7 & 1.0514 & 0.9445 & 1.0223 & 1.0249 & 0.9788 & 0.8560 & 1.3486 & 1.0828 \\
8 & 1.0396 & 0.9868 & 1.0325 & 1.0255 & 0.9591 & 0.8658 & 1.4109 & 1.0322 \\
9 & 1.0708 & 0.9942 & 1.0443 & 1.0200 & 1.0140 & 0.8291 & 1.4559 & 1.0740 \\
10 & 1.0621 & 0.9959 & 1.0488 & 1.0545 & 1.0848 & 0.8119 & 1.5047 & 1.1242 \\
11 & 1.0628 & 0.9952 & 1.0416 & 1.0973 & 1.2152 & 0.8312 & 1.5264 & 1.1318 \\
12 & 1.0708 & 1.0302 & 1.0357 & 1.1492 & 1.3627 & 0.8044 & 1.5020 & 1.1112 \\
\hline & 1.0841 & 1.0539 & 1.0074 & 1.1573 & 1.4512 & 0.7935 & 1.5233 & 1.1086 \\
\hline
\end{tabular}

Note: All MAPPE ratios have been normalized relative to the equivalent symmetric HAR-X model from Table 4.

A value below 1 suggests that the asymmetric HAR-X model provides predictive gains relative to the equivalent symmetric HAR-X model. FT = FTSE100 volatility, XX = EUROSTOXX 50 volatility, BP = GBP/USD volatility, $\mathrm{EC}=\mathrm{EUR} / \mathrm{USD}$ volatility, $\mathrm{CO}=$ Brent crude oil price volatility, $\mathrm{SP}=\mathrm{S} \& \mathrm{P} 500$ volatility, $\mathrm{TY}=\mathrm{US} \mathrm{T}$ bill volatility, GEPU $=$ Global economic policy uncertainty. 
Table 12: Forecast evaluation of monthly European Economic Policy Uncertainty based on the MSPE. Evaluation period:

December, 2011 - August, 2015.

\begin{tabular}{ccccc}
\hline & \multicolumn{2}{c}{ MSPE ratio } & \multicolumn{2}{c}{ MAPPE ratio } \\
\hline $\begin{array}{c}\text { Forecasting } \\
\text { Horizon }\end{array}$ & $\begin{array}{c}\text { Unweighted } \\
\text { Average }\end{array}$ & $\begin{array}{c}\text { Weighted } \\
\text { Average }\end{array}$ & $\begin{array}{c}\text { Unweighted } \\
\text { Average }\end{array}$ & $\begin{array}{c}\text { Weighted } \\
\text { Average }\end{array}$ \\
\hline 1 & $\mathbf{0 . 1 4 8 5}$ & $\mathbf{0 . 1 5 2 9}$ & $\mathbf{0 . 4 2 5 4}$ & $\mathbf{0 . 4 4 0 2}$ \\
2 & $\mathbf{0 . 2 0 3 6}$ & $\mathbf{0 . 2 1 4 0}$ & $\mathbf{0 . 4 8 3 5}$ & $\mathbf{0 . 5 0 6 5}$ \\
3 & $\mathbf{0 . 2 1 5 6}$ & $\mathbf{0 . 2 1 5 8}$ & $\mathbf{0 . 5 1 7 0}$ & $\mathbf{0 . 5 1 9 3}$ \\
4 & $\mathbf{0 . 2 1 7 9}$ & $\mathbf{0 . 2 2 0 1}$ & $\mathbf{0 . 5 2 4 8}$ & $\mathbf{0 . 5 3 7 4}$ \\
5 & $\mathbf{0 . 2 2 0 2}$ & $\mathbf{0 . 2 1 4 5}$ & $\mathbf{0 . 5 4 8 7}$ & $\mathbf{0 . 5 3 6 6}$ \\
6 & $\mathbf{0 . 2 2 1 8}$ & $\mathbf{0 . 2 1 0 2}$ & $\mathbf{0 . 5 5 0 4}$ & $\mathbf{0 . 5 2 5 3}$ \\
7 & $\mathbf{0 . 2 8 9 3}$ & $\mathbf{0 . 2 6 5 5}$ & $\mathbf{0 . 6 3 7 7}$ & $\mathbf{0 . 5 7 0 2}$ \\
8 & $\mathbf{0 . 3 0 3 1}$ & $\mathbf{0 . 2 7 5 8}$ & $\mathbf{0 . 6 5 2 2}$ & $\mathbf{0 . 5 7 1 5}$ \\
9 & $\mathbf{0 . 3 1 9 5}$ & $\mathbf{0 . 2 7 6 1}$ & $\mathbf{0 . 6 7 6 0}$ & $\mathbf{0 . 6 4 9 1}$ \\
10 & $\mathbf{0 . 3 2 7 6}$ & $\mathbf{0 . 2 7 7 3}$ & $\mathbf{0 . 6 8 7 4}$ & $\mathbf{0 . 5 9 9 4}$ \\
11 & 0.4450 & $\mathbf{0 . 3 5 4 7}$ & $\mathbf{0 . 7 9 1 1}$ & $\mathbf{0 . 6 9 1 3}$ \\
12 & 0.5480 & $\mathbf{0 . 3 7 7 5}$ & 0.8885 & $\mathbf{0 . 7 1 8 8}$ \\
\hline
\end{tabular}

Note: All MSPE and MAPPE ratios have been normalized relative to the nochange forecast. Bold face values indicate that the combined forecast is also included in the set of the best models according to the MCS test. 